\title{
Seasonal prevalence of the occurrence of western flower thrips Frankliniella occidentalis (Pergande) (Thysanoptera: Thripidae) on weed hosts growing around ornamental fields
}

\author{
Haruki KATAYAMA* \\ Shizuoka Agricultural Experiment Station; Iwata 438-0803, Japan \\ (Received 13 April 2005; Accepted 5 October 2005)
}

\begin{abstract}
Eighteen weed species were surveyed for western flower thrips (WFT), Frankliniella occidentalis (Pergande) (Thysanoptera: Thripidae), from spring through autumn in 1994 within an ornamental production area in central Japan. WFT were collected from eight weed species and occurred as the predominant thrips species on most of the weed species in April. In early April, the densities of WFT adults and thrips larvae were high on racemes of common groundsel. From April to May, the densities of WFT on flowers of narrowleaf vetch, dandelion, and white clover increased rapidly. Between June and July, WFT adults inhabited predominately the Poaceae weed, but the density of their larvae was low. Furthermore, WFT became the minor colonizers on several weed species from August onward. These results suggest that WFT inhabit and reproduce predominately on numerous weed species flowering around the fields in spring, so the removal of weeds flowering in early spring is important for the control strategy of WFT.
\end{abstract}

Key words: Western flower thrips; weed hosts; seasonal prevalence

\section{INTRODUCTION}

Western flower thrips (WFT), Frankliniella occidentalis (Pergande) (Thysanoptera: Thripidae), were first recorded in Japan in 1990 (Hayase and Fukuda, 1991). This pest has been reported to spread extremely fast throughout most parts of Japan and has become a major pest of ornamentals, vegetables, and fruit crops (Katayama, 1998; Masui, 1998). Subsequently, a report on the first infection of chrysanthemum, Chrysanthemum morifolium, by tomato spotted wilt virus (TSWV) appeared in Shizuoka Prefecture where WFT are abundant (Kato and Hanada, 2000). Recently, TSWV infection has been reported to affect chrysanthemum production in most parts of western Japan (Hanada, 1999).

Since WFT are polyphagous (Brodsgaard, 1989; Hayase and Fukuda, 1991; Tommasini and Maini, 1995), reservoirs are considered to be not only crops, but also wild plants growing around the fields. Several surveys have suggested that the population of WFT present on the surrounding vegeta- tion affects the occurrence of WFT in crop fields (Stoltz and McNeal, 1982; Chellemi et al., 1994; Pearsall and Myers, 2001). Therefore, investigating the population dynamics of WFT within a community of wild host plants growing around fields is very important for developing a strategy for controlling their occurrence on crops. In this study, the fluctuations in the abundance and proportion of WFT were investigated on weed species flowering from spring through autumn in an ornamental production area in which a massive invasion of WFT had occurred.

\section{MATERIALS AND METHODS}

Survey sites. Surveys were conducted in the ornamental production area located on the east coast of Lake Hamanako; chrysanthemum and gerbera, Gerbera spp., are primarily produced in this area in fields and greenhouses throughout the year. In this area, three chrysanthemum fields, two orchards, and three grasslands were selected for the survey.

Plant sampling. Eighteen weed species were

*E-mail: haruki1_katayama@pref.Shizuoka.lg.jp

DOI: 10.1303/aez.2006.93 
inspected twice each month between April and November 1994. For each plant species at each site, flowers, shoots, and whole plants were collected, placed in plastic bags, and transported to the laboratory where they were frozen at $-20^{\circ} \mathrm{C}$; the sampling parts and amounts were dependent on the sampled weed species (Table 1). Incidentally, weed species names are referred to by Shimizu et al. (2001) and the Weed Science Society of Japan (1991). The frozen plant samples were washed with $50 \% \mathrm{EtOH}$ and filtered along with the tissues. By examination under a dissecting microscope, thrips adults were divided into WFT males, WFT females, and adults of other species, and their numbers were counted. The number of thrips larvae was counted, irrespective of the species. Since anthocorid bugs, Orius spp., were collected simultaneously, the number of adults and larvae was also counted, irrespective of the species.

Sticky traps. In order to monitor the seasonal trend, thrips were sampled using a blue sticky trap, consisting of sticky films (Nitto Denko Co.) on both sides of a blue chloroethylene board $(20 \mathrm{~cm} \times 20 \mathrm{~cm}$; Munsell No. 7.3PB3.5/12.7); one trap was placed on a post that was $1 \mathrm{~m}$ higher than the level of vegetation at each site. These were placed in late April, and the thrips caught were collected every 1-2 wk until November. Thrips adults that were caught on the traps were divided into WFT females, Frankliniella intonsa females and others, including Frankliniella males.

\section{RESULTS}

\section{The proportion of WFT to thrips adults occur- ring on weeds}

WFT were recorded from 16 weed species of six families (Table 1). In April, WFT adults were predominant on seven weed species and no other thrips species, specifically, inhabited common groundsel, Senecio vulgaris, annual sowthistle, Sonchus oleraceus and sticky chickweed, Cerastium glomeratum. During May and June, the proportion of WFT on common groundsel, dandelion, Taraxacum officinale, and white clover, Trifolium repens decreased slightly; however, WFT continued to be the predominant thrips species in five of the six weed species studied in June. Between July and August, when the weed composition changed from spring weed species to summer weed species, the proportion of WFT on the weed species of Compositae and white clover decreased to $8-18 \%$ and $33 \%$, respectively, while WFT adults were predominant on the weed species of Poaceae. In September, none of the weeds were detected with WFT. Within grassland, WFT appeared to a lesser extent on tall goldenrod, Solidago altissima, and hairy beggarticks, Bidens pilosa, in October and became predominate on hairy beggarticks and henbit, Lamium amplexicaule, in November. However, WFT continuously occurred on the flowers of chrysanthemum or eggplant, Solanum melongena, from spring through autumn.

\section{Density fluctuations in thrips populations occur- ring on weeds}

The abundance of WFT adults, adults of other species, and thrips larvae collected from weeds that were continuously surveyed three or more times is illustrated in Fig. 1. The densities of WFT adults and thrips larvae on terminals of chrysanthemum stock plants or racemes of common groundsel were higher than those on other sampling plant species, in early April. These densities were found to decrease in late April but leveled off by June. On the other hand, the densities of WFT adults and other species as well as that of thrips larvae on flowers of narrowleaf vetch, Vicia angustifolia, dandelion, and white clover increased rapidly from April to May. However, narrowleaf vetch had died in late May, and dandelion colonies were weeded in late June. Further, the density of WFT on white clover in late June and July decreased and became lower than that of other species, particularly $F$. intonsa. Anthocorid bugs, which are excellent natural enemies of thrips, occurred on white clover from late May to July. The density of WFT adults was high on summer weed species such as barnyardgrass, Echinochloa crus-galli from early June to early July, annual fleabane, Erigeron annuus and green foxtail, Setaria viridis, in late June or early July; however, the density decreased rapidly in late July. Thrips larvae occurred on barnyardgrass and green foxtail, but all of them were distinguished from WFT by their pinkish body color. WFT adults occurred on tall goldenrod in late October and the density of hairy beggarticks increased slightly since late October. 


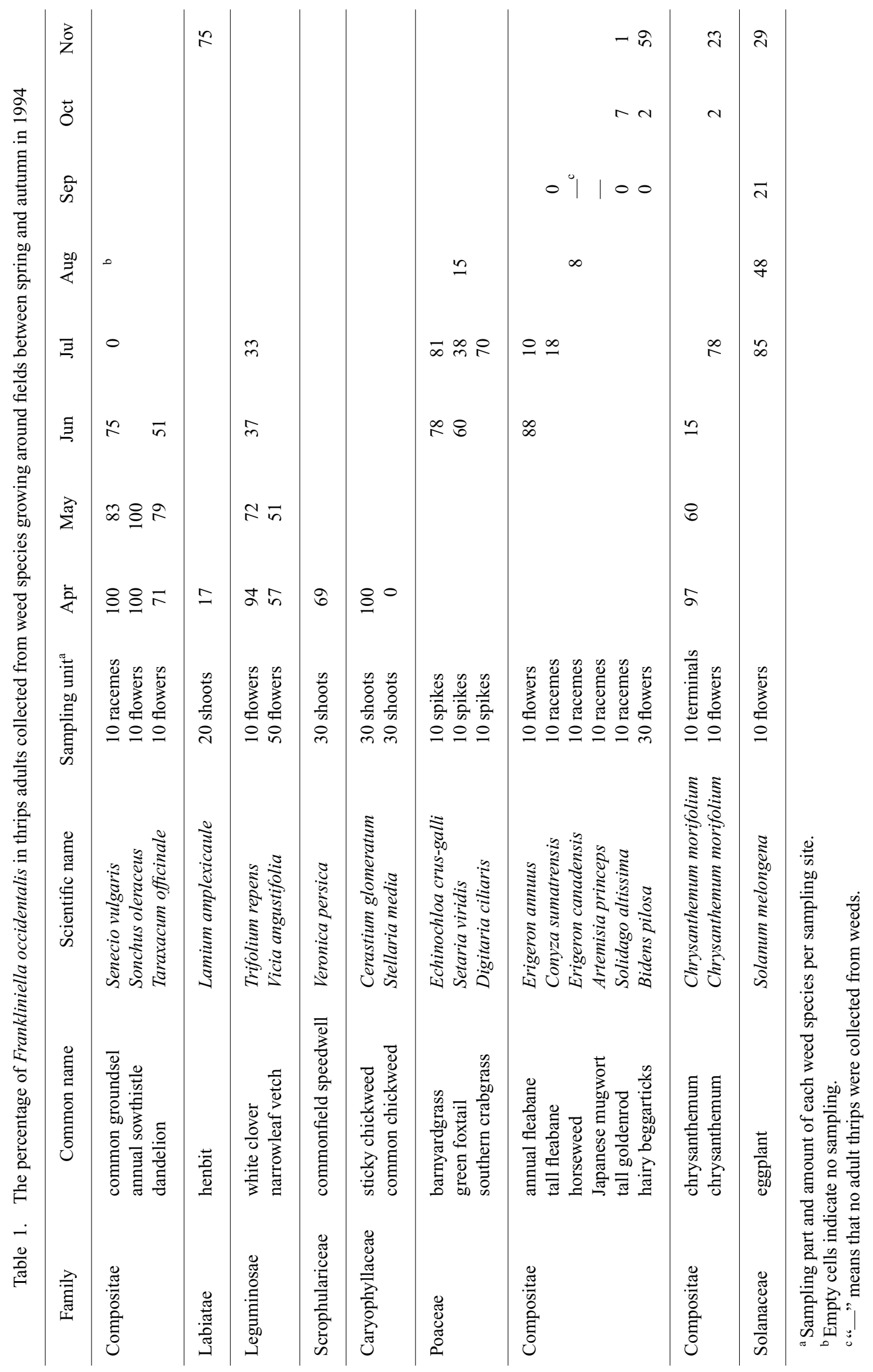




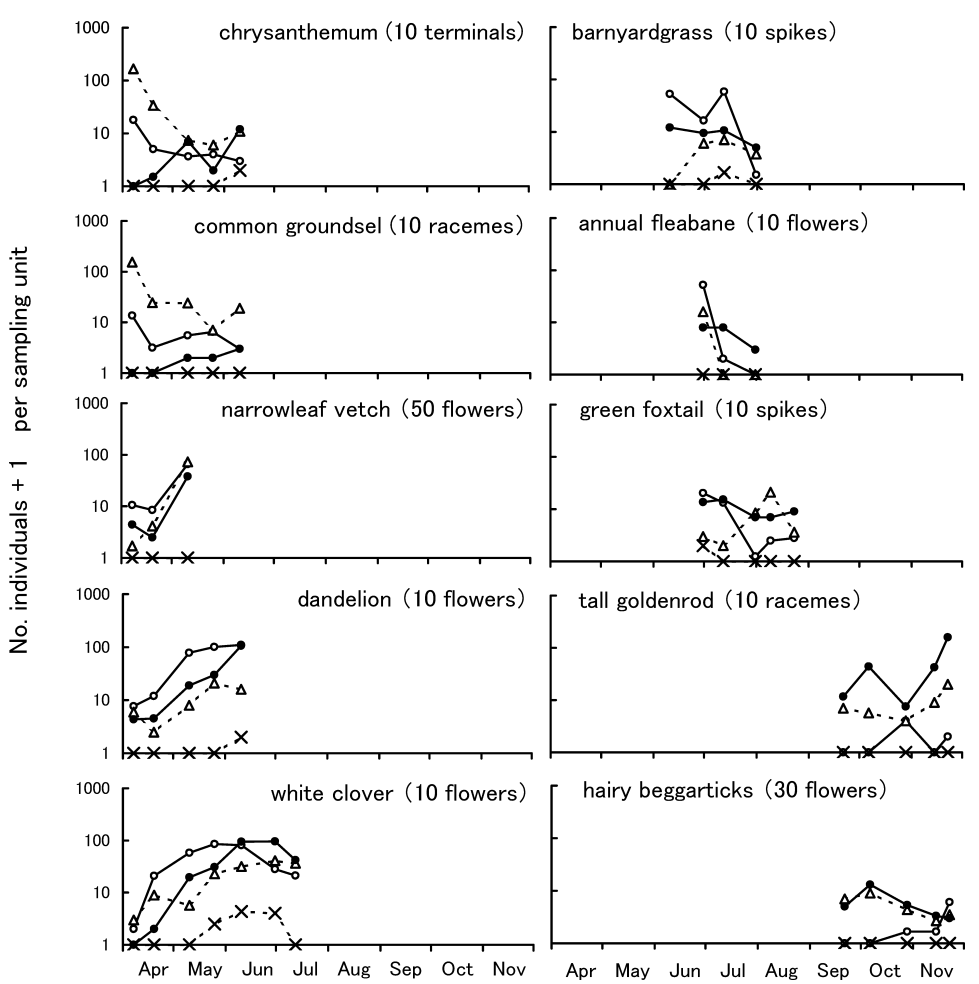

Fig. 1. Abundance of Frankliniella occidentalis adults $(\bigcirc)$, other thrips adults $(\bullet)$, thrips larvae $(\triangle)$, and adults and larvae of anthocorid bugs $(\times)$ collected from flowers of weeds or terminals of chrysanthemum from chrysanthemum fields, orchards, and grasslands in an ornamental production area in 1994. Parentheses indicate sampling part and amount of each weed species per sampling site.

\section{Seasonal trend in abundance of thrips estimated using sticky traps}

WFT adult females were captured using sticky traps from late April onward. Their number was found to increase rapidly and peaked in early June (Fig. 2). The number of adult females of F. intonsa caught from mid-May was identical to that of WFT caught since late June. The number of WFT and $F$. intonsa captured became smaller than that of others from late August onward; however, the capture continued only until November.

\section{DISCUSSION}

Several surveys have been carried out in the United States and Japan to determine the weeds that serve as the source of WFT (Yudin et al., 1986; Chamberlin et al., 1992; Chellemi et al., 1994; Negoro and Shibao, 1998; Gyoutoku and Yokoyama, 1999). Based on these surveys, 118 wild plant species of 37 families were reported as WFT hosts. Moreover, the current survey identified seven additional WFT hosts: common groundsel,

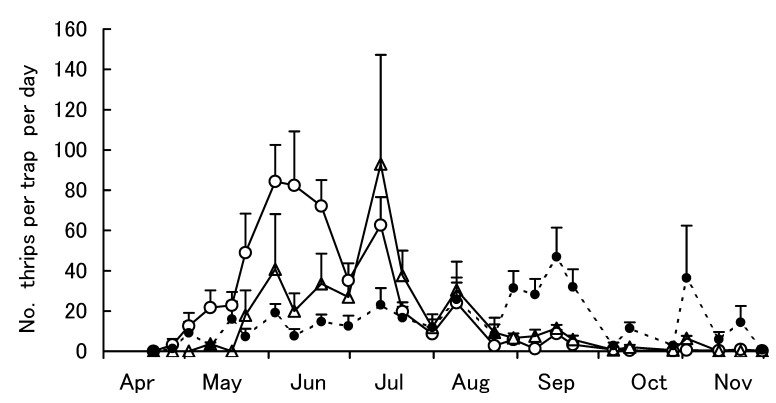

Fig. 2. The seasonal prevalence of occurrence of females of Frankliniella occidentalis $(\bigcirc)$ and $F$. intonsa $(\triangle)$ and adults of other thrips species ( $\bullet$ by the blue sticky trap in the chrysanthemum fields, orchards, and grasslands within the ornamental production area in 1994. Vertical lines indicate the standard error of the mean.

commonfield speedwell, Veronica persica, sticky chickweed, barnyardgrass, southern crabgrass, Digitaria ciliaris, tall fleabane, Conyza sumatrensis, and horseweed, Erigeron canadensis. These results indicate that WFT inhabit numerous weed species around fields.

Surveys conducted in the United States indicated that the important reproductive hosts for WFT in 
Georgia were Trifolium spp. from April to May (Chamberlin et al., 1992) and wild radish, Raphanus raphanistrum, in late winter and spring (Buntin and Beshear, 1995). However, Japanese surveys indicated that the grassland composed of white clover and annual fleabane appeared to be the source of WFT in June (Negoro and Shibao, 1998), also that the reproductive hosts for WFT in citrus orchards were narrowleaf vetch, shepherd's purse, Capsella bursa-pastoris, catchweed bedstraw, Galium spurium var. echinospermon, common venus' looking glass, Triodanis perfoliata, and water foxtail, Alopecurus aequalis var. amurensis, from May to June (Gyoutoku and Yokoyama, 1999). The current survey in the ornamental production area indicated that the most important reproductive hosts of WFT appeared to be common groundsel in April, narrowleaf vetch in April and May, and dandelion and white clover in May and June. This is because WFT adults were predominant among the adult thrips population (Table 1), and the densities of adults and larvae WFT were high on these plants (Fig. 1). Previous reports indicated the weeds with flowers attracted WFT more than the same weeds without flowers (Yudin et al., 1988), the fecundity of WFT adult females rearing on pollens or florets is greater than on leaves (Trichilo and Leigh, 1988; Katayama, 1997). The current survey and former reports suggest these weed species, which commonly flower from April to June, around fields in Japan, can perform the role of reproduction of WFT.

Several reports indicate that the abundance of WFT peaks in spring and bottoms out in summer or autumn in the fields (Salguero Novas et al., 1991; Chellemi et al., 1994; Gyoutoku and Yokoyama, 1999). The current survey conducted using the sticky traps revealed that the seasonal trend in abundance of WFT was similar to that presented in the previous reports (Fig. 2). This result indicates the WFT reproduced on weeds disperses gradually from April to June.

It was indicated that the species composition of Frankliniella thrips varied according to the month, and WFT was more abundant and able to utilize large proportions of the available weed species earlier in the season than other Frankliniella spp. in north Florida (Chellemi et al., 1994). Similar results were obtained from the current survey, which concluded that the proportion of WFT was greater than $50 \%$ on almost all flowering weed species sampled from April to June (Table 1). This result may be influenced by differences in the overwintering biology among the indigenous thrips such as $F$. intonsa. It has been reported that WFT adult females had overwintered dominantly on the stock plants of chrysanthemum and common groundsel, with WFT larvae multiplying rapidly from midMarch (Katayama and Ikeda, 1995). Similarly, in the current survey, it was observed that WFT dominated, and dense populations of larvae occurred on the stock plants of chrysanthemum and common groundsel (Fig. 1). Since WFT do not display diapause (Ishida et al., 2003), they may be able to begin reproduction earlier than the indigenous thrips species, such as F. intonsa, which have reproductive diapause under short-day conditions (Murai, 1988). Therefore, it is considered that WFT can occur and dominate numerous weed species flowering from April to June. This may be one of the factors for the peak abundance of WFT around fields in June.

Gyoutoku and Yokoyama (1999) indicated the reproductive weed species available for WFT did not exist in July, as they were not detected in the weed survey and in the trend captured by the sticky traps. Based on the current survey, WFT became the minor colonizers on several weed species from August onward (Table 1). Furthermore, WFT were not collected in September, except from the crops (Table 1, Fig. 1). Although the density of WFT adults was high on the spikes of the weed species of Poaceae from June to July (Fig. 1), the density of their larvae was low. These results indicate the decrease in the density of WFT during summer is caused by the decrease in the number of preferred weed hosts for WFT.

Other factors for the decrease in WFT occurrence in the summer may be competition between flower-inhabiting thrips and predation by natural enemies. The current survey indicated the proportion of WFT on the weeds decreased from July to September (Table 1), and Orius spp. inhabited white clover during May and June (Fig. 1). It is suggested that the competition for pollen between the flower-inhabiting thrips produces density-dependent reduction in fecundity and growth (Kirk, 1997). However, there is no report to prove this experimentally, and further investigation regarding competition is needed. 
The current survey detected the following features for the seasonal prevalence of WFT in fields (i.e., the increase in densities on several flowering weed species from April to May, to the peak in terms of population in June). These results suggest the WFT can utilize predominately numerous weed species that flower in the spring. Based on these observations, it is suggested that the removal of weeds flowering in early spring is important for the control strategies for WFT.

\section{ACKNOWLEDGEMENTS}

I am grateful to Professor M. Hatsukade and Professor T. Saitou of the Department of Applied Entomology, Shizuoka University, for their critical reading of this manuscript. I am also grateful to Mr. F. Ikeda, the ex-general manager of Shizuoka Agricultural Experiment Station for his valuable advice.

\section{REFERENCES}

Brodsgaard, H. F. (1989) Frankliniella occidentalis - a new pest in Danish glasshouses. Tidsskr. Planteavl 93: 83-91.

Buntin, G. D. and R. J. Beshear (1995) Seasonal abundance of thrips (Thysanoptera) on winter small grains in Georgia. Environ. Entomol. 24: 1216-1223.

Chamberlin, J. R., J. W. Todd, R. J. Beshear, A. K. Culbreath and J. W. Demski (1992) Overwintering hosts and wingform of thrips, Frankliniella spp., in Gerogia: Implications for management of spotted wilt disease. Environ. Entomol. 21: 121-128.

Chellemi, D. O., J. E. Funderburk and D. W. Hall (1994) Seasonal abundance of flower-inhabiting Frankliniella species (Thysanoptera: Thripidae) on wild plant species. Environ. Entomol. 23: 337-342.

Gyoutoku, Y. and T. Yokoyama (1999) Seasonal prevalence and host plants of the western flower thrips, Frankliniella occidentalis (Pergande), in citrus orchards and weed-containing fields around plastic greenhouse containing satsuma mandarin. Kyushu Plant Prot. Res. 45: 105-108 (in Japanese).

Hanada, K. (1999) Tomato spotted wilt virus (TSWV) in the western region of Japan. Plant Prot. 53: 312-315 (in Japanese).

Hayase, T. and H. Fukuda (1991) Occurrence of the western flower thrips, Frankliniella occidentalis (Pergande), on the cyclamen and its identification. Plant Prot. 45: 59-61 (in Japanese).

Ishida, H., T. Murai, S. Sonoda, H. Yoshida, Y. Izumi and H. Tsumuki (2003) Effects of temperature and photoperiod on development and oviposition of Frankliniella occidentalis (Pergande) (Thysanoptera: Thripidae). Appl. Entomol. Zool. 38: 65-68.

Katayama, H. (1997) Effect of temperature on development and oviposition of western flower thrips Frankliniella occidentalis (Pergande). Jpn. J. Appl. Entomol. Zool. 41: 225-231 (in Japanese with English summary).
Katayama, H. (1998) Occurrence and control of western flower thrips, Frankliniella occidentalis (Pergande) on vegetable and ornamentals. Plant Prot. 52: 176-179 (in Japanese).

Katayama, H. and F. Ikeda (1995) Overwintering of western flower thrips, Frankliniella occidentalis (Pergande) in the western region of Shizuoka prefecture. Bull. Shizuoka Agric. Exp. Stn. 40: 63-73 (in Japanese with English summary).

Kato, K. and K. Hanada (2000) A necrotic disease of chrysanthemum (Chrysanthemum morigolium Ramat.) caused by tomato spotted wilt virus (TSWV) in Japan. Kyushu Plant Prot. Res. 46: 61-65 (in Japanese with English summary).

Kirk, W. D. J. (1997) Distribution, abundance and population dynamics. In Thrips as Crop Pest (T. Lewis ed. ). CAB International, London, pp. 217-257.

Masui, S. (1998) Occurrence and control of western flower thrips, Frankliniella occidentalis (Pergande) on fruit tree. Plant Prot. 52: 172-175 (in Japanese).

Murai, T. (1988) Studies on the ecology and control of flower thrips, Frankliniella intonsa (Trybom). Bull. Shimane Agric. Exp. Stn. 23: 1-73 (in Japanese with English summary).

Negoro, M. and M. Shibao (1998) Seasonal prevalence of occurrence of western flower thrips, Frankliniella occidentalis (Pergande), on weeds and eggplant. Proc. Kansai Plant Prot. 40: 135-136 (in Japanese).

Pearsall, I. A. and J. H. Myers (2001) Spatial and temporal patterns of dispersal of western flower thrips (Thysanoptera: Thripidae) in nectarine orchards in British Columbia. J. Econ. Entomol. 94: 831-843.

Salguero Novas, V. E., J. E. Funderburk, S. M. Olson and R. J. Beshear (1991) Damage to tomato fruit by the western flower thrips. J. Entomol. Sci. 26: 436-442.

Shimizu, N., H. Morita and S. Hirota (2001) Photo Guide of 600 Plant Invaders in Japan. Zenkoku Nouson Kyouiku Kyoukai Co., Tokyo. 548 pp. (in Japanese).

Stoltz, R. L. and C. D. McNeal, Jr. (1982) Assessment of insect emigration from alfalfa hay to bean fields. Environ. Entomol. 11: 578-580.

Tommasini, M. G. and S. Maini (1995) Frankliniella occidentalis and other thrips harmful to vegetable and ornamental crops in Europe. In Biological Control of Thrips (J. C. van Lenteren and A. J. M. Loomans eds.). Wageningen Agricultural University Papers, Wageningen, pp. $1-42$.

Trichilo, P. J. and T. F. Leigh (1988) Influence of resource quality on the reproductive fitness of flower thrips. Ann. Entomol. Soc. Am. 81: 64-70.

Weed Science Society of Japan (ed.) (1991) Glossary of the Weed Science. Weed Science Society of Japan, Tokyo. 234 pp. (in Japanese).

Yudin, L. S., J. J. Cho and W. C. Mitchell (1986) Host range of western flower thrips, Frankliniella occidentalis (Thysanoptera: Thripidae), with special reference to Leucaena glauca. Environ. Entomol. 15: 1292-1295.

Yudin, L. S., B. E. Tabashnik, J. J. Cho and W. C. Mitchell (1988) Colonization of weeds and lettuce by thrips (Thysanoptera: Thripidae). Environ. Entomol. 17: 522-526. 